\title{
O MODELO DO CORPO NA FILOSOFIA DE ESPINOSA E A PEDAGOGIA DO COMUM: CONVERSAS COM QUEM GOSTA DE GELEIA DE GROSELHA
}

\author{
Luiz Renato Paquiela Givigi ${ }^{\text {i }}$
}

\begin{abstract}
Resumo: Este texto tem o objetivo de investigar as relações entre mente, corpo, conhecimento e afetividade na obra do filósofo holandês Bento de Espinosa (1632-1677). Busca-se, a partir deste exercício de apreensão conceitual, pensar o estatuto do corpo em sua obra, levantando algumas implicações dessa compreensão para a prática pedagógica. Por extensão, pretende-se articular Espinosa ao tema da educação em geral, vinculação pouco explorada quando comparada a outros pensadores clássicos da história da filosofia. Espinosa não possui uma teoria sobre a educação, no sentido pedagógico tradicional; o tema é pouco mencionado explicitamente em sua obra. Procura-se analisar este problema, levantando algumas pistas para a formulação de um éthos pedagógico inspirado em sua filosofia.
\end{abstract}

Palavras-chave: Espinosa; Corpo; Conhecimento; Educação.

\section{EL MODELO DE CUERPO EN LA FILOSOFÍA DE ESPINOSA Y LA PEDAGOGÍA DE LO COMÚN: CONVERSACIONES CON EL SABOR DE LA GROSELLA}

Resumen: Este texto tiene como objetivo investigar las relaciones entre mente, cuerpo, conocimiento y afectividad en la obra del filósofo holandés Bento de Espinosa (1632-1677). A partir de este ejercicio de aprehensión conceptual, buscamos pensar sobre el estatuto del cuerpo en su trabajo y, a partir de ahí, plantear algunas implicaciones de esta comprensión para la práctica pedagógica. Por extensión, se pretende articular a Spinoza con el tema de la educación en general, un vínculo poco explorado en comparación con otros pensadores clásicos de la historia de la filosofía. Espinosa no tiene una teoría sobre la educación en el sentido pedagógico tradicional; El tema rara vez se menciona explícitamente en su trabajo. Intentamos analizar este problema planteando algunas pistas para la formulación de un ethos pedagógico inspirado en su filosofía.

Palabra clave: Espinosa; Cuerpo; Conocimiento; Educación.

\section{Introdução}

Apesar de não fazer parte do rol de pensadores que figuram na história da educação, quando o assunto é pensar o corpo, Espinosa costuma ser tomado como um aliado no questionamento das práticas que configuram este campo, avaliadas como cartesianas, isto é, como fazeres que desprezam a sensibilidade em nome de uma racionalidade meramente 
instrumental, que privilegiam a mente em detrimento do corpo, a cognição em prejuízo dos afetos, ou que, em suma, privilegiam o indivíduo em relação à coletividade.

Com efeito, espinosismo e cartesianismo costumam emergir como duas linhas paralelas quando se trata de considerar as bases de sustentação do pensamento moderno, bem como das instituições construídas a partir deste. De modo usual, é a partir do grau de aproximação ou de afastamento em relação a uma ou outra destas linhas que se costuma avaliar determinadas práticas sociais, adjetivando-as como cartesianas ou espinosanas; a depender de sua latitude, portanto.

Do ponto geográfico a partir do qual falamos, a saber, mais próximos da linha espinosana, pensamos que tal entendimento não seja errôneo, uma vez que obedece ao princípio da utilidade, auxiliando-nos na vida prática, como dizia Espinosa. Todavia, esse conhecimento precisa ser "emendado", para utilizar um termo do próprio autor. Ou seja, precisa ser acrescentado a uma análise conceitual, uma vez que, assim como não há privilégio da mente sobre o corpo em Espinosa, também não há privilégio do corpo sobre a mente. Trata-se de uma unidade, como buscaremos demonstrar.

Além de não ser tão associado historicamente como um pensador com possíveis contribuições para o campo educativo, Espinosa possui ainda a prerrogativa de ser considerado, entre os próprios filósofos, um anômalo, objeto de ódio e injúrias. Segundo Deleuze (2002, p. 23), tal fato se deve a três denúncias que podem ser extraídas de sua filosofia, quais sejam, a denúncia da 'consciência', dos 'valores' e das 'paixões tristes'.

A consciência como lugar da ilusão, a não existência de valores universais em si e as paixões tristes como correlatos da impotência política seriam as consequências práticas extraídas da filosofia de Espinosa. Porém, a nosso ver, o que há por trás destas três denúncias é o corpo, mas não somente o corpo que temos ou o corpo que nos constitui, mas sim o corpo como um modelo para a filosofia. Eis o escândalo de Espinosa.

Espinosa propõe aos filósofos um novo modelo: o corpo. Propõe-lhe instituir o corpo como modelo: 'não se sabe o que pode o corpo...' Esta declaração de ignorância é uma provocação. Fala-se da consciência e de seus decretos, da vontade e de seus efeitos, dos mil meios de mover o corpo, de dominar o corpo e as paixões - mas nós nem sequer sabemos de que é capaz um corpo. (DELEUZE, 2002, p. 24)

Que quer então dizer Espinosa quando nos convida a tomar o corpo como modelo, pergunta-se Deleuze. É a esta pergunta que buscaremos responder no que se segue abaixo, Revista Interinstitucional Artes de Educar. Rio de Janeiro, V. 5, N.3- pág. 401-422 set-dez de 2019: “Educação: Corpo em movimento." - DOI: 10.12957/riae.2019.45273 
porém não propriamente como filósofos profissionais, mas sim como profissionais da educação, cujo objetivo é a construção de ferramentas que nos permitam analisar e intervir em meio às práticas de trabalho e de vida nas quais nos inserimos. Nesse sentido, e tendo em vista que as entradas são muitas, optaremos por uma inserção pelo tema da educação no pensamento de Espinosa, tema este que, paradoxalmente, só se torna mais concebível a partir de uma análise mais detida sobre os conceitos de corpo, mente, afetividade e conhecimento em sua obra.

\section{Espinosa e a educação: apropriações contemporâneas}

Escritores, poetas, músicos, cineastas e também pintores, inclusive leitores ocasionais, podem se tornar espinosistas, mais do que filósofos de profissão [...] (DELEUZE, 2002, p. 134).

Como já explicitado, Espinosa foi um pensador do século XVII, o que torna o atual interesse por sua obra algo no mínimo curioso. Cerca de três séculos e meio nos separam de Espinosa, e, no entanto, suas palavras parecem referir-se diretamente aos dilemas que vivenciamos no presente. Sua concepção afirmativa da vida em sua incessante produtividade imanente, bem como a contundência de sua crítica às bases de sustentação do pensamento moderno em sua própria aurora, faz de suas ideias ferramentas indispensáveis para se pensar a crise desses mesmos paradigmas na atualidade, bem como a construção de alternativas para os problemas que nos afetam cotidianamente.

Esta peculiaridade da empreitada espinosista, que fez com que Negri (1993) o interpretasse como uma "anomalia" de seu tempo (extemporâneo), tem atraído um número cada vez maior de estudiosos, das mais diversas áreas do conhecimento. A diversidade de campos do saber, bem como dos problemas com os quais a filosofia de Espinosa vem sendo defrontada, se reflete também na multiplicidade de leituras e interpretações de sua obra, o que demonstra sua capacidade de incitar a produção de outros possíveis em cada campo de estudo em particular.

O resgate contemporâneo do espinosismo tornou-se significativo sobretudo a partir da turbulenta década de 60. No Brasil, sua difusão se deve principalmente às obras do filósofo francês Gilles Deleuze (1925-1995). Espinosa e o problema da expressão, publicado em 1968 como segunda tese de doutorado de Estado do autor; Espinosa: Filosofia Prática, de 1970, e a Revista Interinstitucional Artes de Educar. Rio de Janeiro, V. 5, N.3- pág. 401-422 set-dez de 2019: "Educação: Corpo em movimento." - DOI: 10.12957/riae.2019.45273 
transcrição das aulas sobre Espinosa ministradas nos cursos de Vincennes entre os anos de 1978 a 1981 compõem as principais referências nesse sentido. Além deste, podemos destacar ainda pensadores como Ferdinand Alquié, Martial Gueroult, Alexandre Matheron, Pierre Macherey, Antonio Negri, Antônio Damásio, Laurent Bove, entre outros autores que fazem parte dessa reapropriação contemporânea do pensamento de Espinosa.

Pode-se afirmar que a obra de tais pensadores exerceu forte influência na difusão dos estudos espinosanos na academia brasileira, dando ensejo à formação de grupos de estudos, núcleos de pesquisas, revistas dedicadas ao tema, produção de trabalhos acadêmicos em formato de teses e dissertações, congressos e colóquios nacionais e internacionais que reúnem estudiosos de diversas áreas do conhecimento.

Apesar de se tratar das análises de um pensador do campo da filosofia, uma das principais características destes estudos é a diversidade de domínios nos quais ele encontra aplicação ou, mais propriamente, pelos quais ele ganha expressão, marcando assim a natureza transversal do pensamento espinosano ${ }^{2}$.

Com efeito, essa retomada do pensamento espinosano tem se mostrado frutífera nos mais diversos domínios do conhecimento. Entretanto, no que concerne ao campo da educação, esta referência é ainda pouco expressiva quando comparada a outros filósofos. Como notam Santiago e Oliveira (2013), o interesse pelo estudo de Espinosa nas faculdades de educação era raro até dez anos atrás. Foi apenas nesta última década que começaram a surgir alguns estudos mais detidos a esse respeito.

Até onde se sabe, a mais antiga investigação que pretendeu relacionar direta e meticulosamente Espinosa e a educação foi a tese de doutoramento de William Louis Rabenort, intitulada Spinoza as Educator, apresentada à faculdade de filosofia da Universidade de Columbia em 1911. Em 2016, este trabalho foi traduzido para o português e publicado pela EdUECE, reforçando a presente difusão do espinosismo, bem como sua associação com o tema da educação.

Em nossa tese de doutorado, defendida em 2018, havíamos contabilizado cerca de 15 trabalhos, na maioria artigos que, nas últimas duas décadas, buscaram articular Espinosa e Educação, além de um rico dossiê publicado em 2013 pela revista eletrônica da Unicamp, denominado "Espinosa: educação e infância"3, que além de trazer artigos inéditos, republica alguns trabalhos clássicos que se encontram entre aqueles que já havíamos contabilizado. 
Há um amplo espectro de justificativas para dar conta desta pouca aproximação entre o espinosismo e a educação, de modo que cada um dos autores dos trabalhos mencionados acima pôde oferecer a sua. A dificuldade de compreensão da obra de Espinosa, seu pouco tempo de vida, a não importância concedida à infância, o anti-finalismo expresso em sua doutrina, a negativa em ser professor ao recusar uma cadeira na Academia de Heidelberg e as poucas referências diretas ao tema da educação em sua Ética são algumas delas.

Mas é em seu Tratado da Emenda do Intelecto (TIE), também conhecido como cura ou como reforma da inteligência, que o filósofo de Amsterdã descreve de maneira mais explícita a importância da educação para o desenvolvimento da ética ou da liberdade humana. É nesta obra, mais precisamente nos parágrafos 14, 15 e 16, que Espinosa fará menção ao desejo de que muitos pensem como ele, e também a uma "Doutrina da Educação das Crianças".

\begin{abstract}
Eis, pois, o fim a que tendo: adquirir essa natureza e esforçar-me para que, comigo, muitos outros a adquiram: isto é, faz parte de minha felicidade o esforçar-me para que muitos outros pensem como eu e que seu intelecto e seu desejo coincidam com o meu intelecto e o meu desejo; e, para que isso aconteça, é necessário compreender a Natureza tanto quanto for preciso para adquirir aquela natureza; e depois formar a sociedade que é desejável para que o maior número possível chegue fácil e seguramente àquele objetivo. Em seguida, deve dar atenção à Filosofia Moral e também a Doutrina da Educação das crianças; e, como a saúde não é de pequena monta para chagar àquele objetivo, deve-se prepara para isso toda a Medicina... Mas, antes de mais nada, é necessário pensar no modo de corrigir a inteligência e de purificá-la o mais possível desde o início, a fim de que possa compreender com mais facilidade as coisas, sem erro, perfeitamente. (TIE, §§14-16).
\end{abstract}

Como se pode ver, o tema da educação, no Tratado da Emenda do Intelecto, aparece articulado à própria finalidade de sua filosofia, definida como o conhecimento da união da mente com a natureza inteira e o esforço para que outros também o adquiram. Porém, para que tal empreitada seja levada adiante, faz-se necessário primeiro ${ }^{4}$ corrigir o intelecto, e corrigir o intelecto, segundo Espinosa, significa conhecer a própria mente, uma vez que, a partir de suas elaborações, ele havia chegado à conclusão de que os objetos aos quais esta se liga não possuem nada de bom ou de mal em si mesmos, a não ser na medida em que lhe afetavam. Assim, antes de adquirir uma natureza superior (a vida ética) e sua fruição coletiva (comunicá-la aos demais, educar), faz-se necessário corrigir o intelecto. A proposta de demonstrar como Espinosa chegou a estas conclusões no TIE é tão interessante quanto tentadora, porém foge ao escopo de um artigo. Ademais, basta-nos apenas saber que estas são 
como que um prelúdio para sua Ética, onde tais questões serão todas retomadas e rearranjadas numa ordem expositiva própria. Assim, o que queremos enfatizar nesse momento é que, pensar a educação em Espinosa, ou seja, no sentido ético, requer um conhecimento das leis de funcionamento da própria mente, articulando às noções de corpo, conhecimento e afetividade em sua obra. Como afirmou Rezende (2013), "sem que o intelecto esteja de plena posse de seus princípios [...] a moral, a educação das crianças, a medicina e a mecânica poderiam degenera-se em cúmplices da servidão" (p. 87).

\section{A relações entre corpo, mente e conhecimento na Ética de Espinosa}

O livro II da Ética de Espinosa é aquele que se destina a nos explicar "a natureza e a origem da mente". Logo em sua primeira proposição, Espinosa vai afirmar que "O pensamento é um atributo de Deus, ou seja, Deus é uma coisa pensante" (EII, P1) ${ }^{5}$. Diferente do cogito ergo sum cartesiano, que, segundo Espinosa, teria invertido a ordem correta do filosofar ${ }^{6}$, o holandês não vai partir de um sujeito ou de um eu particular para depois chegar ao pensamento. Bem ao contrário, ele parte do pensamento (De Deus) para somente depois chegar ao homo cogitans (o homem pensa), uma vez que para Espinosa o ser humano é um modo, uma afecção da substância Deus. Ao partir de Deus, o que Espinosa faz é desqualificar a consciência humana como suporte isolado do pensar, dessubjetivando o pensamento (o pensamento é uma Res pública, relacionado ao plano do coletivo, do comum).

Deus, como o define na Ética I, é um “ente absolutamente infinito, isto é, uma substância que consiste de infinitos atributos, cada um dos quais exprime uma essência eterna e infinita" (E1, Def. 6). Tais atributos, constituindo a essência da natureza absoluta de Deus, existem necessariamente. Isto é, os atributos constituem a essência mesma da substância, não sendo algo como o seu produto. Assim, tudo o que existe ou é um atributo de Deus ou é uma modificação (afecção) desses mesmos atributos (EI, P14, corol.2), pois Deus é causa imanente e não transitiva das coisas. Dito de outra forma, Deus não se separa da sua criatura, sendo causa de sua existência e, ao mesmo tempo, causa de sua contínua perseverança no existir (EI, P18 e P24, Cor.). A rigor, é a própria ontologia da criação, bem como a da falta, que aqui perde o seu sentido, dando lugar a uma ontologia da produção ${ }^{7}$. Deus não cria nada, mas produz em sendo. 
Dos infinitos atributos que constituem a natureza inteira que é Deus, conhecemos apenas dois, que são pensamento e extensão. Tais atributos, como suposto acima, são essências actuosas que se modificam engendrando tudo o que existe, produzindo mundos (pessoas e coisas). Tudo o que existe, diz Espinosa, exprime a natureza de Deus, ou seja, exprime a sua essência necessariamente, "E não existe nada de cuja natureza não se siga algum efeito" (E1, P36). É por isso que podemos dizer, em termos espinosanos, que existir ativamente significa causar, e não apenas ser causa. Dessa forma, ser um modo ou uma parte finita da potência infinita de Deus é ser um grau de potência que necessariamente afirma algo dela e nela mesma, que produz em sendo. Algo que cria, como é o caso do intelecto, suas próprias verdades. É por existirmos em Deus, como graus de potência da potência infinita, e não por sermos sua criatura, que podemos criar, estilizando nossa potência. Como dissera certa vez Deleuze (2009), Espinosa não abandona Deus porque com Deus tudo é permitido.

De volta à "natureza da mente" na parte II, Espinosa vai nos dizer então que, além de ser uma coisa pensante, Deus é também uma coisa extensa, e que a extensão se explica pela mesma necessidade relativa ao atributo pensamento (EII, P2, Dem.). Assim, tudo o que se segue da necessidade imanente de Deus se expressa simultaneamente a partir dos atributos corpo e pensamento. O homem é uma dessas coisas, isto é, um efeito das modificações definidas dos atributos de Deus. E sua mente é, portanto, uma parte do intelecto divino, assim como o seu corpo o é da extensão. "A ordem e a conexão das ideias é o mesmo que a ordem e a conexão das coisas [...] a substância pensante e a substância extensa são uma só e a mesma substância, compreendida ora sob um atributo, ora sobre outro [...]” (EII, P7 e EII, P7, esc.).

De tudo o que se segue da essência de Deus há portanto uma ideia (EII, P3), e a mente humana é essa ideia, isto é, a mente é uma ideia do corpo existente em ato. Ao definir a mente como ideia do corpo, Espinosa tomará todo o cuidado de ressaltar que esta se diferencia de uma simples percepção, onde a mente seria algo passivo perante o seu objeto, pois é enquanto coisa pensante que esta opera, ou seja, é da necessidade do pensamento formar ideias daquilo que se passa no corpo ${ }^{8}$. Assim, a causa da ideia é sempre outra ideia. Ou melhor, um modo singular do pensar é sempre efeito de uma conexão complexa de outros modos do pensar. Por isso a mente não é uma substância, mas sim um modo do pensar inserido numa rede causal de infinitos outros modos do pensar sem nenhum fundamento transcendente (EII, P9, Dem.), como seria o caso de um sujeito preexistente a este plano.

Reside aqui o sentido da afirmação do TIE, segundo a qual a mente está ligada a um todo que a ultrapassa infinitamente ${ }^{9}$, sendo esta compreensão um dos princípios da reforma do Revista Interinstitucional Artes de Educar. Rio de Janeiro, V. 5, N.3-pág. 401-422 set-dez de 2019: "Educação: Corpo em movimento." - DOI: 10.12957/riae.2019.45273 
intelecto. Mas não é só isso, pois, se por um lado a mente é definida como o efeito de um agenciamento complexo de outras ideias até o infinito, ao mesmo tempo ela não pode deixar de ser concebida como ligada a um corpo, uma vez que "o objeto da ideia que constitui a mente humana é o corpo, ou seja, um modo definido da extensão, existente em ato, e nenhuma outra coisa" (EII, P13). Assim, os pensamentos e as ideias que a mente é determinada a formar têm as afecções do corpo como conteúdo, pois "tudo aquilo que acontece no objeto da ideia que constitui a mente humana deve ser percebido pela mente humana" (EII, P12).

É a própria noção de afeto, definido na EIII como as afecções do corpo e sua ideia, que vai operar esta identidade Os afetos são as variações (transições intensivas) do corpo e sua ideia, e se o corpo não pode determinar a mente a pensar nem a mente pode determinar o corpo ao movimento, é porque estes dizem respeito ao esforço de "uma só e mesma substância”, de modo que é num único e mesmo movimento, como notou Deleuze (2002) ${ }^{10}$, que será possível captar a potência do corpo e a força da mente, donde podemos concluir que o que pode uma mente vai de par como o que pode um corpo, e vice-versa.

Em seu TIE, Espinosa afirmara que a emenda ou a cura do intelecto estava ligada a esses dois pressupostos: que a mente está ligada a um todo que a ultrapassa infinitamente; e que esta ligação está diretamente implicada com algo afetivo, com uma dimensão corporal, podemos dizer agora. Esta é, nos termos do holandês, a natureza superior da mente, isto é, o “conhecimento da união da mente com a natureza inteira". A posse de tal entendimento, ainda segundo Espinosa, nos faria chegar "a compreensão que tudo o que acontece, acontece segundo uma ordem eterna e segundo leis imutáveis da natureza" (TIE, §12), e não em adequação com a consciência humana.

Como afirmamos acima com Resende (2013, p.87), sem que o intelecto esteja de plena posse desses seus princípios, a educação degenerar-se-ia em "cúmplice da servidão". Também Sévérac (2014), num sentido que nos parece semelhante, vai afirmar que pensar a educação como ética, e não como valores morais a serem ensinados ou princípios de conduta a serem inculcados, significa enveredar-se por uma reflexão daquilo que a mente pode fazer "enquanto ela está relacionada com outras mentes”. Isso seria, segundo o autor, afastar-se de um paradigma de inspiração cartesiana que, por um lado, concebe a mente como substancialidade independente e separada do corpo, isto é, do conhecimento como oposto ao afeto; e, por outro lado, concebe o indivíduo como apartado da coletividade. 
[ . ] a mente não é uma substância, por ser inserida numa rede de ideias que a determinam a pensar. Mas a mente não é apenas uma ideia ligada a outras ideias: ela também é uma ideia cujo objeto é o corpo; ela é a consciência, embora geralmente muito limitada, do corpo [...] Posto isso, as ideias (ou os pensamentos que a mente é determinada a formar) têm sim algo do corpo como conteúdo [...] Se o spinozismo é uma verdadeira filosofia do corpo, é porque ele promove este de forma tão nítida que não se pode mais compreender o que uma mente pode, sem compreender simultaneamente o que um corpo pode (e, como se sabe, até agora, ninguém pode determinar o que pode o corpo) (p.160-161).

De forma bastante similar, num texto que se destina a "contribuir para o debate pedagógico na América Latina", Tatián (2015) vai dizer que se existe uma filosofia espinosana da educação, voltada para a emancipação intelectual e, portanto, ética, esta filosofia espinosana da educação consistiria numa compreensão voltada precisamente para 0 modelo do corpo do qual falamos acima.

Nadia, hasta ahora, ha determinado lo que puede la Mens [...] Lo que puede decirse del cuerpo puede decirse de la mente, no porque sean entidades paralelas sino precisamente porque son lo mismo [...] esa naturaleza pensante está sin embargo abierta a una indeterminación radical, a una vulneración, a un despojo, también a una aventura y una construción. No sabemos lo que puede una inteligência, La inteligência de cualquiera (p.1).

Como nota o autor, dizer que o homem pensa (homo cogitat), na forma de um axioma, como aparece na EII, é afirmar algo que se revela por si mesmo, que não requer demonstração. Assim, "homo cogitat" é uma condição comum de todos os homens que, em seu laconismo, quer dizer que essa natureza pensante do homem está aberta a uma indeterminação ética radical, equivalente à consagrada expressão espinosista segundo a qual não sabemos o que pode um corpo (EIII, P2, esc.). Em outras palavras, se não podemos determinar antecipadamente o que pode o corpo, também não podemos determinar o que pode a mente.

Desse modo, o problema pedagógico poderia ser situado numa modificação desta conhecida passagem relativa ao corpo sem que, no entanto, ela perdesse todo o seu sentido: "Não sabemos o que pode uma inteligência" assim como não sabemos o que pode um corpo, uma vez que se trata de uma unidade. Com efeito, e sob esse aspecto, o que não se pode dizer do corpo é o mesmo que não se pode dizer da mente. Afirmação de ignorância que é, ao mesmo tempo, uma declaração de confiança, uma indeterminação emancipadora relativa à sua potência indefinida de pensar e criar. Declaração de ignorância que é, como afirmou Deleuze 
(2002), o correlato da afirmação especulativa, de uma verdadeira ética do conhecimento enquanto experimentação.

Dada esta segunda característica da mente, desse modelo que vai de par com o que pode o corpo, Espinosa vai dizer então que seu conhecimento está condicionado a uma compreensão precisa da natureza do corpo, e, para além disso, que a própria diferença entre uma ideia e outra, bem como a superioridade de uma mente sobre outra mente, está sujeita ao conhecimento da natureza de seu objeto que é o corpo (EII, P13, esc.).

Digo, porém, que, em geral, quanto mais um corpo é capaz, em comparação com outros, de agir simultaneamente sobre um número maior de coisas, ou de padecer simultaneamente de um número maior de coisas, tanto mais sua mente é capaz, em comparação com outras, de perceber, simultaneamente, um número maior de coisas [...] É por esses critérios que podemos reconhecer a superioridade de uma mente sobre as outras, bem como compreender por que não temos de nosso corpo senão um conhecimento muito confuso, além de muitas outras coisas, as quais deduzirei, a seguir, do que acabo de expor (EII, P13, esc.).

É nas teorizações que se seguem ao escólio da P13 da EII, conhecidas como sua pequena física, que Espinosa definirá o que é um corpo. “Os corpos se distinguem uns dos outros em razão do movimento e do repouso, da rapidez e da lentidão, e não em razão da substância" (EII, P13, Ax. 2, Lem1). Um corpo não é uma substância ou uma coisa separada das outras, mas um modo, uma parte intensiva de um todo do qual depende seu esforço de perseverar no ser, seu movimente e seu repouso, sua velocidade e sua lentidão. Essa diferenciação relativa ao movimento, segundo Espinosa, é aquilo que se refere sobretudo aos corpos mais simples (que, embora em graus variados, são todos animados, isto é, possuem pensamento). Todavia, há ainda os corpos mais compostos, cuja distinção, por sua vez, darse-á pelo seu grau de composição.

Quando corpos quaisquer, de grandeza igual ou diferente, são forçados, por outros corpos, a se justaporem, ou se, numa outra hipótese, eles se movem, seja com o mesmo grau, seja com graus diferentes de velocidade, de maneira a comunicarem seu movimento uns aos outros segundo uma proporção definida, diremos que esses corpos estão unidos entre si, e que, juntos, compõem um só corpo ou indivíduo, que se distingue dos outros por essa união de corpos (EII, P13, Def.).

O corpo humano é um desses corpos compostos, e o que diferencia sua mente das outras mentes, bem como sua superioridade com relação às outras coisas animadas, é 
precisamente esse grau de composição ou essa multiplicidade convergente de corpos ou de indivíduos que o constitui, uma vez que o que caracteriza a relação entre corpo e mente é uma união.

\begin{abstract}
Post. 1. O corpo humano compõe-se de muitos indivíduos (de natureza diferente), cada um dos quais é também altamente composto. Post. 3. Os indivíduos que compõem o corpo humano e, consequentemente, o próprio corpo humano, são afetados pelos corpos exteriores de muitas maneiras. Post. 4. O corpo humano tem necessidade, para conservar-se, de muitos outros corpos, pelos quais ele é como que continuamente regenerado. Post. 6. O corpo humano pode mover e arranjar os corpos exteriores de muitas maneiras.
\end{abstract}

É a partir destas postulações que Espinosa chegará à conclusão, logo nas proposições seguintes (P14 e P15 da EII), de que quanto mais composto for um indivíduo, maiores são as coisas que sua mente pode perceber, ao mesmo tempo em que também podem ser maiores seus conflitos, como já fora indicado no final do escólio da própria P13. Os corpos afetam-se mutuamente, compõem-se, decompõem-se, formam indivíduos mais complexos, destroem outros, agenciam-se parcialmente a alguns, são indiferentes a outros. São em si mesmos já uma multiplicidade que se relaciona com outras, que, por sua vez, possuem também graus variados de composição.

E o que é a mente humana? A mente humana é a ideia deste regime complexo de afecções variáveis entre os corpos. Como diz Espinosa, "A ideia que constitui o ser formal da mente humana á a ideia do corpo, o qual compõe-se de muitos indivíduos altamente compostos [...] A ideia que constitui o ser formal da mente humana não é simples, mas composta de muitas ideias" ${ }^{11}$, donde podemos concluir que a mente humana é a ideia de uma multidão de corpos. Eis o que é prodigioso no modelo do corpo, como disse Deleuze (2002, p. 25), "esses conjuntos de partes vivas que se compõem e decompõem segundo leis complexas". E, acrescentemos, abertos a uma indeterminação radical.

\title{
A dimensão afetiva da relação pedagógica e a produção do conhecimento como fabricação do comum
}

Se considerarmos apenas a mente dos homens, pode-se dizer que, sem dúvida, eles não erram; se parecem, entretanto, errar, é porque julgamos que 
eles têm na mente exatamente os mesmos números que estão no papel. Se não fosse essa última circunstância, não acharíamos que eles erram, exatamente como não julguei que estivesse errado alguém que ouvi, recentemente, gritar que o seu pátio tinha levantado vôo em direção à galinha do vizinho, pois sua mente me parecia suficientemente clara(EII, P46, escol.).

O título deste ensaio possui uma dupla inspiração: a obra do notório educador brasileiro Rubem Alves (1933-2014), denominada “Conversas com quem gosta de ensinar", e um pequeno comentário de Gilles Deleuze (1925-1995), onde o mesmo, ao ser perguntado sobre sua relação intelectual com o psicanalista Félix Guattari (1930-1992), isto é, ao ser questionado sobre como se instruíam mutuamente e produziam seus conceitos e suas obras, responde dizendo que, caso dissesse a Guattari que no centro da terra contém geleia de groselha, a função deste seria a de ajudá-lo a provar.

A questão não é 'discutir'. Se Félix me disser alguma coisa, eu só tenho uma função: busco o que pode confirmar uma ideia tão bizarra ou louca (e não 'discutível'). Se eu lhe dissesse: 'no centro da terra tem geleia de groselha', seu papel seria buscar o que poderia dar razão a uma ideia como essa. É o contrário, pois, de uma sucessão ou troca de opiniões [...] e, aliás, uma objeção nunca será feita. Só haverá melhora" (DELEUZE Apud MAGGIORI, 2015, p. 167) ${ }^{12}$.

É com este mesmo espírito que o educador brasileiro Ruben Alves, na obra mencionada acima, busca contrapor aquilo que chama de espírito da ciência, por um lado, e espírito da conversa, por outro. A primeira forma, a partir de um modo específico de se relacionar com verdade, produz um "discurso sem respostas", com tendências ao silenciamento do outro, diz Alves (1980). "Isso não está correto", “isso é falso", "isso é um absurdo", "isso é verdadeiro", são alguns de seus enunciados. Já a segunda, a forma conversa, persegue um tipo de verdade que é da ordem da continuidade e da composição, uma questão de "gosto", no sentido de fazer valer alegrias relacionadas aos diversos sentidos do corpo, como no caso da geleia que se busca "provar" em Deleuze e Guattari. Questão de experimentação.

Conversa é pra quem gosta, nos lembra Rubem Alves, e deste ponto de vista o provar não mais se reduz aos rigores assépticos das ciências tradicionais, isto é, daquelas que privilegiam a mente em detrimento do corpo, a cognição em relação aos afetos. É nesse 
sentido que o mesmo autor vai dizer que neste outro estilo de condução em relação à verdade, não se diz "isso é mentira" ou "isso é verdade", mas sim que aquilo que o outro diz pode ser melhorado, acrescentado, donde os anunciados do tipo: “isso ainda não é nada", "nem te conto", "e tem mais", “e não para por aí”. Ou seja, são maneiras de se compor com o outro, dando continuidade a uma relação como obra aberta, cujo efeito é a construção de planos existenciais cada vez mais complexos e alargados ${ }^{13}$. "Aquele que começa oferece um tema, dá um ponto, e passa a agulha ao outro... E assim a coisa vai sendo feita, como tarefa de muitos" (ALVES, 1980, p. 3).

O que se nos apresenta aqui é, ao mesmo tempo, uma indicação de cunho pedagógico, ético e epistemológico. Ou, dito de outro modo, ao mesmo tempo em que estas colocações desenham o horizonte de um certo modo de se relacionar com a verdade, esboçam também um certo tipo de relação interpessoal que seria necessário estabelecer para que dela possamos nos aproximar, ou seja, um tipo de relação pedagógica. A condição de possibilidade de uma relação de aprendizado mútuo bem como da construção do próprio conhecimento passa então por um certo regime afetivo de composição dos corpos, sendo a ideia verdadeira, no sentido espinosano, seu correlato. É a partir desse ajuste de corpos que surge a possibilidade de expansão da mente, uma vez que ela é a ideia do corpo. Trata-se, portanto, de uma questão de método, e não de uma moral do respeito mútuo, ou de indulgência para com aquilo que o outro traz, como se costuma dizer no meio educacional escolarizado.

A partir dos três afetos primários, quais sejam o desejo (cupiditas), a alegria e a tristeza (EIII, P11, esc.), Espinosa construirá toda uma arquitetura de nossa existência. Nosso desejo, ou nossa potência de agir, de afetar e ser afetado varia em função dos encontros que vamos fazendo com os outros entes, uma vez que só existe desejo agenciado. À medida que esses encontros aumentam nossa potência de agir, vivenciamos uma alegria (composição), caso contrário, experimentamos tristeza (decomposição). O sentir e o pensar relacionados a essa experiência são indissociáveis, uma vez que a mente é a ideia do corpo. Habitamos relações de forças afetivas que necessariamente contrariam ou contribuem para a nossa perseveração em nosso próprio ser, para nosso esforço (conatus) de agir. Somos, portanto, uma potência de afecção, uma potência de encontro, uma capacidade de afetar e ser afetado, e quanto mais elevado é esse poder, maior será nossa capacidade de agir e de pensar (EIV, P38).

Mas o que se passa entre esse plano afetivo, no qual somos atingimos de formas variadas, e a nossa capacidade de pensar, de inteligir? Ou seja, como podemos pensar melhor? Revista Interinstitucional Artes de Educar. Rio de Janeiro, V. 5, N.3- pág. 401-422 set-dez de 2019: "Educação: Corpo em movimento." - DOI: 10.12957/riae.2019.45273 
Obviamente, nos afetando melhor, isto é, fazendo composições que aumentem tal disposição de nosso corpo a afetar e a ser afetado, a agir. É por isso que dissemos acima que para Espinosa a superioridade de uma mente está ligada a seu grau de composição. Como comenta Bove (2010), dependendo do grau de aumento dessa capacidade de afetação, "pode ocorrer um fenômeno de complexificação, de multiplicação, de variação: essa rede se torna mais densa e mais articulada. Rede de que? Das nossas aptidões de afetar e sermos afetados, simultaneamente. Quando isso acontece a partir de um limiar, podemos ter um tipo de ideia a que Espinosa denomina “ideias verdadeiras'” (p.29-30). Caso contrário, quando essa potência de agir é constrangida ou diminuída, experimentamos tristeza, cujo correlato intelectual é o que Espinosa chama de "ideia inadequada"14. Toda ideia expressa um estado afetivo de nosso corpo, do modo como este é afetado em ato (pedagogos ou psicólogos bem experimentados costumam saber disso). Não mais garantia de verdades universais, a razão em Espinosa significa então essa potência de afetar, de produção de efeitos e afetos em meio a outros entes singulares, "significa ser mobilizado, modificado, transformado, tocado" (BOVE, 2010). Ora, na medida que nossa potência de agir é uma questão de agenciamento - já que somos sempre com o outro- o pensamento será sempre concebido como construção de estratégias no plano do coletivo, e nunca uma questão relacionada a faculdades privadas.

Tais características ficam bem nítidas nos extratos das entrevistas de Deleuze e Guattari reunidas por Maggiori (2015), relativas às maneiras de instruir-se mutuamente, onde aparece a imagem da geleia de groselha: “A questão não é saber se a opinião é minha ou dele [...] Guattari estava dizendo: trata-se de uma 'afinação', de um ajuste. Feito o ajuste, nascem então todos os conceitos que estão fervilhando" (p. 167).

Como se pode ver aqui, o ato pedagógico, quando acontece, é como efeito de uma certa composição de corpos que aumenta a potência e, simultaneamente, expande a capacidade de inteligir. O acontecimento pedagógico constitui-se, portanto, como uma qualidade intensiva (aumento de potência) que se passa entre os corpos, num plano sempre comum, incitando-os a ação, ao pensar ativo. Entretanto, uma das principais características dessa expansão, que em Espinosa pode também ser definida como um maior grau de perfeição ou de liberdade, é que ela não é redutível aos fins pré-estabelecidos pelas políticas pedagógicas de Estado que, como afirmaram Deleuze e Guattari (2012), só admitem uma imagem do pensamento, qual seja, aquela que se identifica com ele mesmo, transformando as singularidades compositivas em uma unidade, rebatendo-as sobre a imagem representativa de 
um povo submetido a um poder separado, isto é, transcendente a esta dinâmica mesma das forças em composição ${ }^{15}$. Como definiu Rancière (2002) a propósito de uma educação emancipadora,

\begin{abstract}
Quem ensina sem emancipar, embrutece. E quem emancipa não tem que se preocupar com aquilo que o emancipado deve aprender. Ele aprenderá o que quiser, nada, talvez. Ele saberá que pode aprender porque a mesma inteligência está em ação em todas as produções humanas, que um homem sempre pode compreender a palavra de um outro homem (p. 30)
\end{abstract}

Acontece que essa sintonia intensiva, ou estes estados afetivos comuns de aumento da potência articulada a uma experiência compositiva do pensar, são mais fáceis de ser concebidos do que encontrados no cotidiano. Como pensou Espinosa, isso acontece justamente por sermos seres afetivos, e por estarmos geralmente submetidos a paixões tristes engendradas por um campo social desfavorável, como é o caso do capitalismo contemporâneo, por exemplo. Daí que os humanos, por mais que precisem uns dos outros para cultivar o corpo e a mente, e apesar de não duvidarem dos benefícios advindos da concórdia, costumam ser mais invejosos que generosos, mais afeitos à disputa e à competição do que à generosidade e à ajuda mútua, como acontece em nossas escolas e academias.

É nesse sentido que este pôde dizer que os homens combatem por sua servidão como se fosse por sua liberdade (TTP, prefácio, p. 08), ou então que, apesar de viverem entre muitos, experimentam uma solidão, ou um deserto de sociabilidade (TP, V, §4) ,aquilo que Espinosa concebe como uma animalização (TTP, cap. XX, p. 302). Para Espinosa, é importante explicitar, não é a falta de conhecimento que embrutece e faz o rebanho, mas sim um regime afetivo que implica um deserto de sociabilidade (EIV, P70). Ou seja, mesmo na mais profunda ignorância, os homens demonstram ser capazes de ajuda e aprendizado mútuo, sendo esse seu vetor de humanidade e, por consequência, o valor de uma educação. $\mathrm{O}$ conhecimento pelo conhecimento não possui valor ético, nem tampouco potência de transformação.

A esta dificuldade político-social, e do ponto de vista da relação pedagógica propriamente dita, pode-se ainda ser acrescentado o fato de os corpos-mentes serem compostos por uma multiplicidade de corpos-mentes que se ligam a outros corpos-mentes e assim até o infinito (EIII, P13). Caracterizada por uma relação de aliança e confronto, de composição e decomposição, a ligação entre estes é marcada então por amplas variações, a ponto de serem levados até mesmo a sua própria destruição, como é o caso das doenças Revista Interinstitucional Artes de Educar. Rio de Janeiro, V. 5, N.3- pág. 401-422 set-dez de 2019: "Educação: Corpo em movimento." - DOI: 10.12957/riae.2019.45273 
autoimunes, onde alguns corpos-mentes em conjunto passam a ser reconhecidos como estranhos ao todo do qual faziam parte. Isso quanto a um indivíduo humano considerado particularmente. Se considerarmos agora a complexidade envolvida num encontro de dois ${ }^{16}$, de uma sala de aula ou quem sabe de uma instituição educativa inteira, podemos imaginar as dificuldades de ajuste envolvidas nessas relações, quando nosso horizonte é o de promover bons encontros, aumentando assim nossa potência de pensar. Sem contar que, devido à natureza múltipla, variável e transitória de tais agenciamentos de corpos-mentes, aquilo que compõem ou que alegra parte de um corpo-mente pode não alegrar outras partes deste mesmo corpo-mente, ou então que um contentamento de hoje pode já não ser o de amanhã, e viceversa.

A partir do exposto acima, podemos pensar então que essa pedagogia do comum, baseada na potência, na sensibilidade e na generosidade, tal como a vida social em geral, é mais fácil de ser concebida que encontrada. Mas esse é, em todo caso, o próprio desafio de uma pedagogia pensada a partir da ética espinosana, onde se diz que o caminho que conduz à beatitude é tão difícil quanto raro. Do contrário, diz Espinosa, como se explica que este caminho seja negligenciado por quase todos ${ }^{17}$

Dada a dificuldade exposta acima, relativa a esta dimensão conflitiva e indeterminada inerente às relações humanas, Espinosa, inspirado em sua leitura de Maquiavel $^{18}$, que ele denominou "arguto florentino", nos oferece uma passagem que, a nosso ver, pode ser transposta para nossas práticas pedagógicas, sejam elas em uma sala de aula, em uma roda de conversa, em um conselho de classe, em um grupo de estudos, de discussão de casos, entre outros. Remetendo-nos a história romana, Espinosa nos diz: Porque se é verdade que enquanto os romanos deliberam Sagunto perece,
também é por outro lado verdade que, se forem poucos a decidir tudo de
acordo apenas com o seu afeto, perece a liberdade e o bem comum. Os
engenhos humanos são, com efeito, demasiado obtusos para que possam
compreender tudo de imediato; mas consultando, ouvindo e discutindo, eles
aguçam-se e, desde que tentem todos os meios, acabam por encontrar o que
querem, que todos aprovam e em que ninguém havia pensado antes (TP, IX,
14).

Ora, o que se pode ver aqui, mais uma vez, é o elogio da multiplicidade como garantia da liberdade, da produção do comum e, sobretudo, como metodologia de fabricação do impensado. E isso vale tanto para um único indivíduo humano considerado particularmente quanto para um grupo destes. A multiplicação dos sentidos e das diferenças, por mais Revista Interinstitucional Artes de Educar. Rio de Janeiro, V. 5, N.3- pág. 401-422 set-dez de 2019: "Educação: Corpo em movimento." - DOI: 10.12957/riae.2019.45273 
incoerentes e contraditórios que possam parecer (como no caso do pátio que voou na galinha do vizinho), funciona não só como garantia de liberdade, mas também como estratégia de produção do novo, estilização que pode ser pensada como a máxima potência.

Este é, em todo caso, o próprio modelo do corpo do qual falávamos acima, essa multiplicidade de partes vivas abertas a um plano de produção que existe e ao mesmo tempo precisa ser experimentado e construído na micropolítica de nosso cotidiano, uma vez que não sabemos o que pode um corpo. Se, como diz Espinosa, o caminho é tão árduo quanto raro, vale a pena procura-lo, pois deve ser certamente árduo aquilo que tão raramente se encontra.

\section{Considerações finais}

Podemos dizer que educar-se, do ponto de vista de uma ética da liberdade, significa desenvolver certa aptidão para habitar o conflito nas relações com os outros e consigo mesmo (já que somos muitos). É nesse sentido que dizíamos, com Espinosa, que sem a cura ou a reforma do intelecto a educação tornar-se-ia cúmplice da servidão, uma vez que, eliminando sumariamente os conflitos, as contradições, e as diferenças, acabamos nos enveredando pela dominação do um que sabe e que manda, e dos outros que não sabem, e portanto, obedecem. Mais do que isso, buscar eliminar sumariamente as dores e as contendas envolvidas nesta dinâmica é eliminar a própria possibilidade de aprendermos com elas, de estabelecermos o comum e de construirmos uma saúde longe dos processos de medicalização da vida que nos espreitam. Enquanto muitos tomam remédios para ensinar e aprender, ou para se adaptar à maneira como a escola moderna organizou o aprendizado, Espinosa nos propõe uma maneira de conhecer que precisa ser em si mesma um remédio para nossa existência (EV, P4, esc.). Do contrário, tal não deveria ser chamado de conhecimento, mas receber outro nome. $\mathrm{O}$ conhecimento deve ser útil (aumentar a potência) e, mais do que isso, precisa estar implicado com uma alegria comum, com uma certa maneira de viver bem com os outros, em ato.

Isso porque, em Espinosa, não há uma tendência essencial no humano que o impeliria à busca da verdade num campo puramente epistemológico e, portanto, neutro e desinteressado. O que há de essencial é um “desejo de viver feliz ou de viver e agir bem [...], que é a própria essência do homem, o esforço pelo qual cada um se esforça por conservar o seu ser”, aquilo que Espinosa denomina conatus (esforço) (EIV, P21, Dem.). Esse esforço por conservar-se, por aumentar sua alegria e repelir a tristeza, relativo ao direito natural de cada Revista Interinstitucional Artes de Educar. Rio de Janeiro, V. 5, N.3-pág. 401-422 set-dez de 2019: "Educação: Corpo em movimento." - DOI: 10.12957/riae.2019.45273 
coisa é a própria essência do homem, constituindo-se assim como o motor de todos os processos, incluindo o educativo. Não o desejo de aprender, mas sim o desejo de viver bem, de aumentar a alegria e combater a tristeza ${ }^{19}$. Como afirma Sévérac (2009),

Ao contrário de Pascal, para quem a segunda natureza do homem, nascida do pecado, é marcada especialmente pela libido sciend, ou ainda, de Hobbes, que define a curiosidade como um amor do conhecimento natural do Homem, Spinoza [...] não faz alarde nunca, na Ética de certa forma de afetividade que disporia o homem naturalmente, e favoravelmente, para o conhecimento (p. 20).

O conhecimento verdadeiro, enquanto verdadeiro ${ }^{20}$, isto é, sem que ele esteja implicado com uma dinâmica afetiva própria ao conatus de cada coisa, isto é, a sua utilidade, não tem valor ético, nem tampouco força de libertação ${ }^{21}$, o que daria no mesmo, uma vez que a ética espinosista visa a liberdade. Ao discutir o problema do conhecimento em Espinosa, Sévérac (2009) dará todo o destaque a este ponto:

Até a última proposição, Spinoza mantém essa ideia: o que nos salvará, não é o vão esforço, nascido talvez do conhecimento claro de nossos impedimentos, para nos livrar dos maus afetos; mas o gozo de certa forma de afetividade, que então nos dará a força de experimentar menos aquela que não faz a nossa felicidade (p.18).

Não se trata, com efeito, de conhecer qualquer coisa, de conhecer por conhecer, de buscar conhecer tudo, de acumular conhecimentos ou mesmo de conhecer uma verdade fundamental até então escondida. Trata-se do gozo de certa forma de afetividade que se dá num jogo de forças afetivas, e sempre políticas, portanto. Se há um paradigma para a aquisição do conhecimento em Espinosa (e por conseguinte para o instruir-se mutuamente, como é o caso da educação), podemos dizer que ele está assentando no critério rigoroso da utilidade imanente dos modos singulares em suas relações com outros modos singulares, de modo que este conhecimento, enquanto um bem, precisa ser um bem comum, uma vez que o verdadeiro bem ou o Summum bonum perseguido como um remédio em seu trabalho sobre a cura do intelecto tem como prerrogativa a comunicabilidade ${ }^{22}$. O bem verdadeiro é, por natureza, comum, comunicável, composição afetiva que faz proliferar esse conjunto de partes vivas que nos constitui. 


\section{REFERENCIAS}

ALVES, R. Conversas com quem gosta de ensinar. São Paulo: Editora Cortez, 1980.

BOVE, L. Espinosa e a psicologia social: ensaios de ontologia política e antropogênese. Belo Horizonte: Autêntica, 2010.

BOVE, L. Da confiança política: construir a Hilaritas democrática. Tradução: Bernardo Bianchi. In: GRASSET, B. N. A.; FRAGOSO, E. A. R.; ITOKAZU, E. M.; GUIMARÃES, F.; ROCHA, M. (orgs.) Spinoza e as Américas: Vol. 2. Fortaleza: EdUECE, 2014, p. 215 235 .

CHAUÍ, M. Laços do desejo. In: NOVAES, A. (Org). O Desejo. São Paulo: Companhia das Letras, 1990.

COLERUS, J. Vida de Spinoza. Tradução: Emanuel Angelo da Rocha Fragoso. Disponível em: <http://benedictusdespinoza.pro.br/biografias-de-spinoza-colerus.html>. Acesso em: 20 de out de 2019.

DELEUZE, G. Cursos sobre Spinoza (Vincennes, 1978-1981). Tradução: Emanuel Angelo da Rocha Fragoso e Hélio Rebello Cardoso Junior. Fortaleza: EdUECE. Coleção Argentum Nostrum, 2009.

. Espinosa e o problema da expressão. Tradução: GT Deleuze. Coordenação de Luiz B. L. Orlandi. São Paulo: Editora 34, 2017.

Espinosa: filosofia prática. Tradução: Daniel Lins e Fabien Pascal Lins. São Paulo: Escuta, 2002.

DELEUZE, G.; GUATARRI, F. Mil platôs: capitalismo e esquizofrenia 2, Vol.1. Tradução: Ana Lúcia de Oliveira, Aurélio Guerra Neto e Celia Pinto Costa. São Paulo: Editora 34, 2011.

. Mil platôs: capitalismo e esquizofrenia 2, vol.5. Tradução: Peter Pál Pelbart e Janice Caiafa. São Paulo: Editora 34, 2012.

ESPINOSA, B. Tratado Político. Tradução: Diogo Pires Aurélio; revisão Homero Santiago. São Paulo: Martins Fontes, 2009.

. Tratado Teológico Político. Tradução: Diogo Pires Aurélio. São Paulo: Martins Fontes, 2003.

. Tratado da Reforma da Inteligência. Tradução: Lívio Teixeira. São Paulo: Martins Fontes, 2004.

MAGGIORI, R. Conversas com Deleuze e Guattari no jornal parisiense Libération (12 de setembro 1991), p. 17-19. In: Revista Trágica: estudos de filosofia da imanência, vol. 8, nº 2, p. 164 - 168 , out.-dez. 2015. Traduzido por Guilherme Ivo e Mariana de Toledo Barbosa. Disponível em http://tragica.org/artigos/v8n2/traducao.pdf. Acesso em: 10 set. 2019. 
MAQUIAVEL, Nicolau. Discurso sobre a primeira década de Tito Lívio. Tradução:

Martins Fontes. São Paulo: Martins Fontes, 2007.

NEGRI, A. A anomalia selvagem: poder e potência em Spinoza. Tradução: Raquel Ramalhete. Rio de Janeiro: Editora 34, 1993.

RABENORT, W. L. Spinoza como educador. Tradução: GT Benedictus de Spinoza (Coordenação Emanuel Angelo Fragoso/Francisca Juliana Barros Sousa Lima). Fortaleza: EdUECE, 2016.

RANCIÈRE, J. O mestre ignorante: cinco lições de emancipação intelectual. Tradução: Lilian do Valle. Belo Horizonte: Autêntica, 2002.

REZENDE, C. N. A gênese textual da doutrina da educação das crianças no Tratado da Emenda do Intelecto de Espinosa. In: Espinosa: educação e infância. Revista eletrônica de filosofia e educação da Unicamp, V 5, n. 1, p. 52-110, 2013. Disponível em https://www.fe.unicamp.br/revistas/ged/rfe/issue/view/262. Acesso em: 10 set. 2019.

SANTIAGO, H. S. e OLIVEIRA, F. B. Educação e Infância em Espinosa. Revista eletrônica da Unicamp. Filosofia e Educação, v. 5, n. 1, p. 1 - 7, 2013. Disponível em https://www.fe.unicamp.br/revistas/ged/rfe/issue/view/262. Acesso em: 10 set. 2019.

SÉVÉRAC, P. Conhecimento e afetividade em Spinoza. In: MARTINS, A. (org) O mais potente dos afetos: Spinoza e Nietzsche. São Paulo: Martins Fontes, 2009.

A educação como ética: Spinoza e Vygotsky. In: GRASSET, B. N. A.; FRAGOSO, E. A. R.; ITOKAZU, E. M.; GUIMARÃES, F.; ROCHA, M. (orgs.). Spinoza e as Américas: Vol. 2. Fortaleza: Ed. UECE, 2014.

SPINOZA, B. Ética. Tradução: Tomaz Tadeu. Belo Horizonte: Autêntica, 2009.

Obra completa II: correspondência completa e vida. Guinsburg, J.; Cunha, N.; Romano, R. (orgs.). Tradução: Guinsburg, J.; Cunha, N. São Paulo: Perspectiva, 2014.

Tratado Teológico-Político. Tradução: Diogo Pires Aurélio. São Paulo: Martins Fontes, 2003.

TATIÁN, Diego. Homo cogitat: igualdad spinozista de las inteligências. XII Colóquio Internacional Espinosa e as Américas. Córdoba-ARG, 2015. (comunicação oral).

\footnotetext{
i Doutor em psicologia pela Universidade Federal Fluminense e psicólogo do quadro efetivo da Secretaria Municipal de Educação da Cidade do Rio de Janeiro. Rj, Brasil. E-mail: renatogivigi@gmail.com. ORCID: https://orcid.org/0000-0003-4896-5461.

${ }^{2}$ No endereço http://spinozamericas.blogspot.com.br/ o leitor pode encontrar reunidas as informações a respeito dos principias eventos, grupos de estudo e publicações existentes em torno da filosofia de Espinosa. Acesso em: 10 Set. 2019.

Revista Interinstitucional Artes de Educar. Rio de Janeiro, V. 5, N.3-pág. 401-422 set-dez de 2019: "Educação: Corpo em movimento." - DOI: 10.12957/riae.2019.45273
} 


${ }^{3}$ Esta publicação encontra-se disponível no endereço eletrônico:

https://www.fe.unicamp.br/revistas/ged/rfe/issue/view/262. Acesso em: 10 Set. 2019.

${ }^{4}$ Vale ressaltar que o "antes" aqui não diz respeito a um exercício de preparação que antecede a vida mesma, como é o caso da moratória social produzida pela escolarização moderna. Curar a inteligência diz respeito a uma maneira de viver, no sentido de uma dietética na relação com pessoas e coisas.

${ }^{5} \mathrm{O}$ sistema de referenciação dos estudos espinosanos convencionado por seus estudiosos e indicado pelo próprio Espinosa se organiza da seguinte forma: E - Ética Demonstrada em Ordem Geométrica (P - Proposição; A Apêndice; Ax. - Axiomas; Cor. - Corolário; Def. Af. - Definição dos Afetos; Def. - Definição; Dem. Demonstração; Ex. - Explicação; Pref. - Prefácio; L - Lema; Esc. - Escólio); TP - Tratado Político (Cap. e parágrafos); TIE - Tratado da Emenda do Intelecto (parágrafos), TT-P - Tratado Teológico Político (Cap. e páginas).

${ }^{6}$ EII, P10, esc.

${ }^{7}$ Segundo Chaú (1990, p. 60), a grande novidade do espinosismo seria esta, ou seja, a de imprimir o infinito no finito, de conceber os modos finitos como determinações do próprio infinito.

${ }^{8}$ EII, P5, Cor. e EII, Def. 3, onde se diz: "Por ideia compreendo um conceito da mente, que a mente forma porque é uma coisa pensante. Explicação. Digo conceito e não percepção, porque a palavra percepção parece indicar que a mente é passiva relativamente ao objeto, enquanto conceito parece exprimir uma ação da mente".

${ }^{9} T I E \S 12$ e $\$ 13$.

10 "É, pois, por um único movimento que chegaremos, se for possível, a captar a potência do corpo para além das condições dadas do nosso conhecimento, e a captar a força da mente, para além das condições dadas da nossa consciência" (Deleuze, 2002, p 24).

${ }^{11}$ EII, P15, esc.

12 Esses trechos compõem um texto montado de conversas com Deleuze e Guattari, recolhidas por Robert Maggiori, no jornal parisiense Libération (12 de setembro 1991), p. 17-19. Estes foram traduzidos para o português e publicados em Revista Trágica: estudos de filosofia da imanência (MAGGIORI, 2015).

${ }^{13}$ Cabe-nos ao menos fazer notar, uma vez que esta inflexão nos faria ultrapassar o escopo de um artigo, que este modo específico de se relacionar com o saber e com os outros pode também ser extraído dos eventos cotidianos da vida de Espinosa, ou seja, na forma como ele mesmo se comunicava com seus pares, seus opositores intelectuais, e também com pessoas comuns. Espinosa não está alinhado com a tradicional imagem do filósofo solitário e sisudo. Seu pensamento e sua obra foram constituídos e constantemente reformulados à base de comunicações intensas. Numa de suas inúmeras trocas epistolares, por sinal com um de seus opositores, um teólogo calvinista de nome William de Blyenbergh, Espinosa deu a esta relação o nome de "erudição mútua" (erudire possimus), daí nos utilizarmos desta noção ao longo do texto (Obra Completa II, p. 129, Ep. 21). Foram muitos aqueles com que o pensador de Amsterdã pode estabelecer tal relação. Albert Burgh, Oldenburg, Boxel, De Vries, Tschirnhaus, Boreel, Balling, Koerbagh, Bouwmeester, Meyer, Jelles, apenas para citar alguns que fizeram parte daquilo que podemos chamar de círculo de amigos de Espinosa. A título de exemplo, gostaríamos de mencionar, todavia, o famoso episódio da viúva Van Velden, uma pessoa comum. Indo morar em Haia, Espinosa ficou alojado em sua pensão por um curto período de tempo. Já tendo notícias da posição crítica de Espinosa com relação às escrituras sagradas, esta o questiona se poderia ser salva através da religião que seguia. Espinosa, mesmo tendo uma maneira diversa de pensar esta questão, não busca persuadi-la às suas opiniões, respondendo apenas: "Vossa religião é boa, vós não deveis procurar outra nem duvidar que vós não obtenhais vossa salvação, contanto que ao vos dedicar à piedade, vós leveis ao mesmo tempo uma vida agradável e tranquila" (Colerus, 2015). Como podemos perceber, essa não seria a imagem típica de um professor, que tradicionalmente, como um pastor, se esforça em transmitir aquilo que acredita ser a verdade, ainda que de formas mais abrandadas, lúdicas, pseudodemocráticas, ou ao gosto do freguês, como se passa no contemporâneo. Ora, como já o vimos, a atitude de Espinosa assenta-se em sua concepção imanente de conhecimento, relativa a um afetar-se melhor que corresponde a própria noção de verdade. Desse modo, enquanto a Sra. Van Velden o questiona sobre as consequências de se substituir uma verdade transcendente por outra, Espinosa, como um exímio educador, a responde de forma imanente, compositiva. Ou seja, se aquilo em que acredita a faz bem, não há porque mudar. Em Espinosa, o sábio é aquele que alcançou o gozo de uma certa forma de afetividade, enquanto o vulgo é aquele que vive oscilando de uma verdade transcendente a outra, acreditando apenas aquilo que ainda não o enganou, coisa que as religiões, os políticos e os marqueteiros sabem muito bem como aproveitar.

14 "Por afeto compreendo as afecções do corpo, pelas quais sua potência de agir é aumentada ou diminuída, estimulada ou refreada, e, ao mesmo tempo, as ideias dessas afecções. Explicação. Assim, quando podemos ser Revista Interinstitucional Artes de Educar. Rio de Janeiro, V. 5, N.3- pág. 401-422 set-dez de 2019: "Educação: Corpo em movimento." - DOI: 10.12957/riae.2019.45273 
a causa adequada de alguma dessas afecções, por afeto compreendo, então, uma ação; em caso contrário, uma paixão". (EIII, Def. 3). "A nossa mente, algumas vezes, age; outras, na verdade, padece. Mais especificamente, à medida que tem ideias adequadas, ela necessariamente age; à medida que tem ideias inadequadas, ela necessariamente padece (EIII, P1). As ações da mente provêm exclusivamente das ideias adequadas, enquanto as paixões dependem exclusivamente das ideias inadequadas (EIII, P3).

15 O termo "pensamento de Estado" é utilizado por Deleuze e Guattari (2012) e refere-se a uma imagem de pensamento emprestado pelo aparelho de Estado, que fixa para estes caminhos, objetivos, canais e imagens. $\mathrm{O}$ pensamento de Estado é aquele que visa retirar o caráter plural das singularidades imanentes em composição (multitudinárias), bem como a diversidade de modos de vida daí decorrentes, para rebatê-la numa noção abstrata e unificada de povo, ligada a transcendência de um poder fixado como soberania. É assim que toda a diversidade dos modos em composição e seu porvir serão esmagados em nome de uma massa de indivíduos que formam uma unidade representativa denominada povo. Esse é o truísmo mais basilar que a escola moderna, democrática e para povo, pode representar. A escola do povo ensina a ser povo, visa transformar a multidão em povo. A noção de multidão, em Espinosa, remete precisamente as forças de composição solidárias do comum que resistem a esta fixação.

16 "Escrevemos o Anti-Édipo a dois. Como cada um de nós era vários, já era muita gente" (DELEUZE; GUATTARI, 2011, p. 17).

17 "Se o caminho, conforme já demonstrei, que conduz a isso parece muito árduo, ele pode, entretanto, ser encontrado. E deve ser certamente árduo aquilo que tão raramente se encontra. Pois se a salvação estivesse à disposição e pudesse ser encontrada sem maior esforço, como explicar que ela seja negligenciada por quase todos?" (EV, P42, esc.).

18 É interessante lembrar que, para Maquiavel (2007), “os bons exemplos nascem da boa educação; a boa educação, das boas leis; as boas leis, dos tumultos que muitos condenam sem ponderar [...] os desejos dos povos livres raras vezes são perniciosos à liberdade, visto que nascem ou de serem oprimidos ou da suspeita de que virão a sê-lo" (MAQUIAVEL, 2007, p. 4).

19 "Nada, certamente, a não ser uma superstição sombria e triste, proíbe que nos alegremos. Por quê, com efeito, seria melhor matar a fome e a sede do que expulsar a melancolia? Este é o meu princípio e assim me orientei" (EIV, P45, esc. 2).

${ }^{20}$ É o célebre verso de Ovídio, mencionado por diversas vezes na Ética, que vai dar o tom desta problemática: Video meliora proboque, deteriora sequor. Isto é, "vejo o que é melhor e o aprovo, mas sigo o que é pior".

${ }^{21}$ EIV, P1. "Nada do que uma ideia falsa tem de positivo é suprimido pela presença do verdadeiro enquanto verdadeiro. Escólio: [...] E, igualmente, as outras imaginações que enganam a mente, quer indiquem o estado natural do corpo, quer indiquem um aumento ou uma diminuição de sua potência de agir, não são contrárias ao verdadeiro nem se desvanecem por sua presença $[\ldots]$ "..

${ }^{22} T I E \S 1$. 